\title{
Variation of soil fertility and carbon sequestration by planting Hevea brasiliensis in Hainan Island, China
}

\author{
CHENG Chun-man ${ }^{1}$, WANG Ru-song ${ }^{1, *}$, JIANG Ju-sheng ${ }^{2}$ \\ 1. Research Center for Eco-Environmental Sciences, Chinese Academy of Sciences,Beijing 100085, China. E-mail: chcmhn@yahoo.com \\ 2. Research and Development Center of Hainan State Farm Bureau, Haikou 570212, China
}

Received 6 April 2006; revised 12 May 2006; accepted 1 June 2006

\begin{abstract}
The development of rubber industry depends on the sustainable management of rubber plantation. To evaluate the environmental effects of planting Hevea brasiliensis on a subsystem of tropical forest ecosystem, the variation of soil fertility and carbon sequestration under rubber plantation within 30-year life period were investigated in Hainan Island. Results showed that (1) with the increase of stand age of rubber plantation, soil fertility decreased all along. From 1954 to 1995, soil organic matter, total N, available K and available $\mathrm{P}$ decreased by $48.2 \%, 54.1 \%, 56.7 \%$ and $64.1 \%$, respectively. (2) If the complete return of litters was considered without additional fertilizer application to the soil of the rubber plantations, the consumption periods for $\mathrm{P}, \mathrm{N}, \mathrm{K}, \mathrm{Mg}$ were only 825 years, 329 years, 94 years and 65 years, respectively. To improve soil fertility is essential for rubber plantation development. (3) The C sequestration of rubber trees per hectare accounts for $272.08 \mathrm{t}$ within 30 -year life period and $57.91 \%$ of them was fixed in litters. In comparison with $\mathrm{C}$ sequestration by rain forest $\left(234.305 \mathrm{t} / \mathrm{hm}^{2}\right)$ and by secondary rain forest $\left(150.203 \mathrm{t} / \mathrm{hm}^{2}\right)$, rubber forest has more potentials for C fixation. On the base of above results, the following measures would benefit the maintenance of soil fertility and the development of rubber industry, including applying fertilizer to maintain the balance of soil nutrients, intercropping leguminous plant to improve soil fertility, reducing the collection of litters, optimizing soil properties to improve element $\mathrm{P}$ availability such as applying $\mathrm{CaCO}_{3}$. The information gathered from the study can be used as baseline data for the sustainable management of rubber plantation elsewhere.
\end{abstract}

Key words: soil fertility; carbon sequestration; rubber plantation; Hainan Island

\section{Introduction}

Land use change may influence environment, many natural phenomena and ecological processes (Turner, 1989), including soil condition (Fu et al., 2000), biodiversity (Liu et al., 2001) and carbon sequestration as well (Dale, 1997).

The introduction of Hevea brasiliensis leads to a significant change of land use and cover in Hainan Island, which is a typically tropical rubber-producing arbor and was firstly introduced from Malaysia in 1906 (He and Huang, 1987). Since the 1950s, the rubber plantation has been developed rapidly at the cost of decreasing tropical natural forests and shrubs in Hainan Island. In 2001, the rubber plantation covered $3.7 \times 10^{5} \mathrm{hm}^{2}$, accounting for $11.6 \%$ of the total land area of Hainan Island and becoming the largest artificial ecosystem in Hainan Island (Jiang and Wang, 2003). Rubber plantation in Hainan Island is generally distributed in the region between the central mountainous area and the coastal area (Fig.1). In Hainan Island the rubber production is $2.9 \times 10^{5} \mathrm{t} / \mathrm{a}$ in 2001, making up $60 \%$ of the total production of China (Jiang and Wang, 2003).

With the development of rubber plantation, many studies

Project supported by the National Natural Science Foundation of China (No. 70433001).*Corresponding author. E-mail: wangrs@ @rcees.ac.cn. were carried out to improve rubber production, including soil and water loss, soil fertility, and growth characteristics (Jarin, 1996; Dea, 1997; Luo, 1983). But it has not been studied the long-term environmental changes on soil fertility and carbon sequestration led by planting rubber trees. Rubber plantation has the purpose for latex extraction and rubber trees have its natural lifetime for 30 years. Due to the extraction of latex and removal of biomass for rubber plantation, the nutrient loss in the soil of rubber plantation and change of carbon sequestration in relation to substituted natural forests are obvious, even though long-term or life-time quantified research on these is not yet available before this study. The objectives of this study were to assess variations in soil fertility and carbon sequestration after other vegetation types were substituted by rubber plantation in Hainan Island, and further to provide fundamental data for the sustainable management of rubber plantation.

\section{Materials and methods}

\subsection{Description of the study area}

The research was carried out in Hainan Island $\left(18^{\circ} 10^{\prime}-\right.$ $20^{\circ} 10^{\prime} \mathrm{N}$ and $\left.108^{\circ} 37^{\prime}-111^{\circ} 03^{\prime} \mathrm{E}\right)$, which covers 33920 


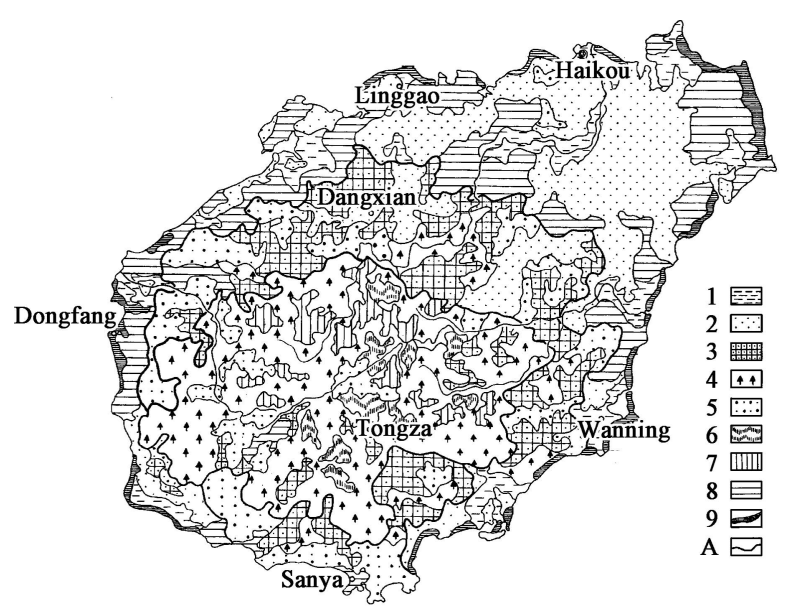

Fig. 1 Land use types in Hainan Island in 1997. (1) paddy field; (2) arid land; (3) rubber plantation; (4) timber forest; (5) scrub land; (6) grassland; (7) barren land; (8) wasteland; (9) shelter forest belt; (A) boundary of link (Jiang and Wang, 2004).

$\mathrm{km}^{2}$ of land area and was situated in the southernmost province of China. The central Five Finger Mountain is the highest in the island with an altitude of $1867 \mathrm{~m}$ above sea level. The climate of the area is tropical monsoon with average annual rainfall $1600-2500 \mathrm{~mm}$ and average annual temperature $23-25^{\circ} \mathrm{C}$. While the lowest monthly average temperature is $17-20^{\circ} \mathrm{C}$ (Jiang and Wang, 2003).

\subsection{Soil sampling and processing}

Three data sources analyzed in this study for soil fertility include the general soil survey of Hainan Island in 1982 and the field investigation dataset in 1954, 1990 and 1995 conducted by Hainan State Farm Bureau and the Rubber Cultivation Research Institute, Chinese Academy for Tropical Agricultural Sciences, respectively.

In 1954, the large-scale rubber plantation was planted in about 50 state farms in Hainan Island. A general soil fertility survey to rubber reclamation areas was conducted and these data provide a general view on the soil fertility condition in the first batch of state farms before rubber planted. From data of the general soil survey of Hainan Island in 1982, the part of soil fertility data collected from the first reclaimed 50 state farms are used in relation with later investigations.

To make samples reasonable and representative, sample sites were chosen according to soil types before field investigation on rubber plantation. The rubber plantations were divided into four soil type areas according to parent rocks, including granite, basalt, metamorphic rock, sandy shale and alluvium in Hainan Island. Since the most favorable soil for rubber plantation in Hainan Island is the soil with parent rock granite, the first established farms were located in the areas of this type soil. In total, 50 soil profiles under 30 -years stand age of rubber plantation were sampled and analyzed. For each profile triplicate samples using 0-40 $\mathrm{cm}$ depth mixed soil were taken and the nutrient indices, such as organic matters, total $\mathrm{N}$, available $\mathrm{P}$ and available $\mathrm{K}$, and $\mathrm{Mg}^{2+}$, were analyzed by the methods descried as the follows.

Soil organic matter was determined by the oil bath-
$\mathrm{K}_{2} \mathrm{Cr}_{2} \mathrm{O}_{7}$ titration method. Total nitrogen was determined by the semi-micro Kjeldahl method. Available nitrogen was determined by a micro-diffusion technique after alkaline hydrolysis. Total phosphorus was determined colorimetrically after wet digestion with $\mathrm{H}_{2} \mathrm{SO}_{4}+\mathrm{HClO}_{4}$. Available phosphorus was extracted with $0.5 \mathrm{~mol} / \mathrm{L}$ $\mathrm{NaHCO}_{3}$ solution ( $\mathrm{pH}$ 8.5). Phosphate-P in solution was determined colorimetrically by the formation of the blue phosphomolybdate complex following reduction with ascorbic acid. Total potassium was determined by the Cornfield method. Available potassium was determined by $\mathrm{CH}_{3} \mathrm{COONH}_{4}$ extraction method. $\mathrm{Mg}^{2+}$ was extracted from the soil with normal neutral ammonium acetate was analyzed by atomic absorption spectroscopy (AAS, Z8000, Hitachi, Japan).

\subsection{Carbon sequestration calculation and vegetation investigation}

\subsubsection{Sampling and calculation of $\mathrm{C}$ sequestration}

The standard sample wood biomass methods by Sivakumaran et al. (2000) was adopted for estimating the $\mathrm{CO}_{2}$ fixation by rubber plantations.

In this study, the standard sample trees with the average breast diameter $(20 \mathrm{~cm})$ and 30 years stand age were chosen in five rubber farms. Triplicate samples were taken from roots, stem, main branch, secondary branch, tertiary branch, fresh branch and leaves from each sample tree. Samples were then processed and analyzed in the laboratory. Finally $\mathrm{C}$ sequestration in forms of biomass per hectare rubber trees $\left(C_{\mathrm{Bi}}\right)$ is calculated by the following equation:

$C_{\mathrm{Bi}}=A \times C_{\text {ave }}$

where $A$ is the number of rubber trees per hectare, in Hainan Island, usually as $375 ; C_{\text {ave }}$ is the amount of carbon content in the standard sample rubber wood.

$\mathrm{C}$ sequestration by latex tapping $\left(C_{\mathrm{La}}\right)$ can be estimated by the following equation:

$C_{\mathrm{La}}=R \times P \times N$

where $R$ is the average $C$ content in latex, value $88 \%$ is applied (Sivakumaran et al., 2000); $P$ is the average annual output of latex per hectare, $1172.35 \mathrm{~kg} / \mathrm{hm}^{2}$ in 2000 in Hainan; $N$ is the economic lifetime of average rubber trees, 25 years in Hainan (He and Huang, 1987).

Litter from rubber trees also contributes to $\mathrm{C}$ sequestration. Litter sampling was taken under above-mentioned standard sample trees. Five hundred grams of each litter samples from L (layer of non-decomposed), F (layer on the process of decomposing) and $\mathrm{H}$ (layer of decomposed) layers under each standard sample tree were taken. Collected litters were taken to laboratory to be processed and measured. $\mathrm{C}$ sequestration by litter from rubber trees $\left(C_{\mathrm{Li}}\right)$ can be estimated by the following equation:

$C_{\mathrm{Li}}=B \times K \times M$

where $B$ is the average litter biomass in per hectare rubber farm, in Hainan $9.34 \mathrm{t} /\left(\mathrm{hm}^{2} \cdot \mathrm{a}\right) ; K$ is the average $\mathrm{C}$ content 
from the litter biomass, $53.3 \%$ in Hainan (Sivakumaran et al., 2000); $M$ is the natural lifetime of rubber trees, 30 years in Hainan.

Finally, C sequestration by rubber plantation per hectare $\left(C_{\mathrm{R}}\right)$ as a whole can be calculated by the following equation:

$C_{\mathrm{R}}=C_{\mathrm{Bi}}+C_{\mathrm{La}}+C_{\mathrm{Li}}$

\subsubsection{Nutrient cycle estimation for rubber plantation}

Nutrient cycle observation was carried out in the experimental rubber farm in Danzhou, Hainan Island, China by the Rubber Cultivation Research Insitute (RCRI) between 1989-1991. Nutrients fixed by rubber trees, seeds and litters were measured with samples of standard rubber trees from 6 age groups (1-30 years). Nutrients removed from latex tapping were estimated by the data of total rubber plantation area, average production of latex tapping and average nutrient content of latex. Nutrients returned from litters were measured by samples under standard rubber trees of 6 age groups (5-30 years). Nutrients returned from rainfall were measured with rainfall samples from open spaces in the experimental rubber farm. Biological $\mathrm{N}$ fixation was measured in the experimental rubber farm by RCRI, the three year measurement result is $6.6 \mathrm{~kg} /\left(\mathrm{hm}^{2} \cdot \mathrm{a}\right)$. Additional nutrients supplemented from fertilizer application were estimated by the amount of compound fertilizer applied to the farm, and the nutrient content of the compound fertilizer. The overall analysis was carried out in relation with ratio of area for each age group of the total
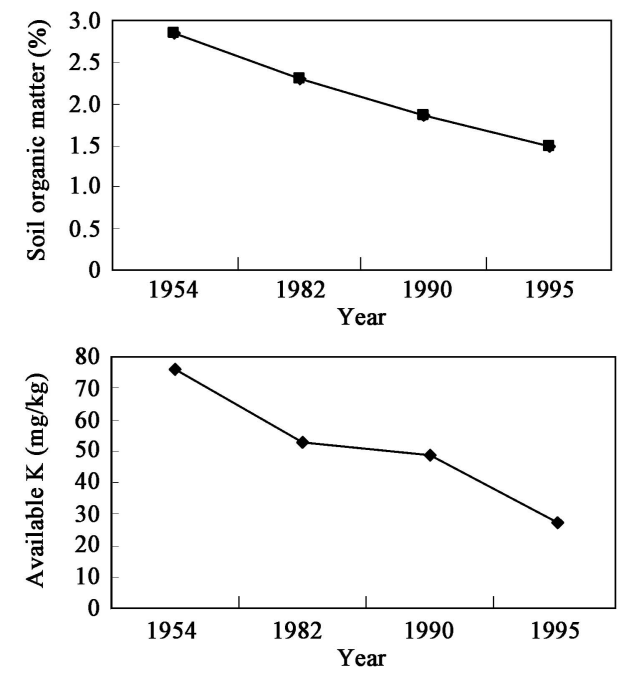

Fig. 2 Changes of soil chemical properties under rubber plantation during 1954-1995 in Hainan Island.

Table 1 Degradation rates of soil fertility under rubber plantations in Hainan Island

\begin{tabular}{|c|c|c|c|c|c|}
\hline \multirow[t]{2}{*}{ Parameter } & \multirow[t]{2}{*}{ Reference system } & \multirow[t]{2}{*}{ Natural soil (\%) } & \multicolumn{3}{|c|}{ Rubber plantation soil (\%) } \\
\hline & & & 1982 & 1995 & Average annual declining rate $(\%)$ \\
\hline Organic matters & Percentage over soil of $\geqslant 2 \%$ & 75.5 & 66.2 & 10.3 & 4.3 \\
\hline Total N & Percentage over soil of $\geqslant 0.1 \%$ & 52.6 & 44.5 & 14.0 & 2.3 \\
\hline Total P & Percentage over soil of $\geqslant 0.14 \%$ & 3.69 & 2.37 & 0 & - \\
\hline Total K & Percentage over soil of $\geqslant 1.2 \%$ & 82.9 & 78.3 & 40.0 & 2.9 \\
\hline Available N & Percentage over soil of $\geqslant 60 \mathrm{mg} / \mathrm{kg}$ & 89.9 & 80.1 & 42.2 & 2.9 \\
\hline Available P & Percentage over soil of $\geqslant 5 \mathrm{mg} / \mathrm{kg}$ & 62.1 & 59.4 & 10.0 & 3.8 \\
\hline Available K & Percentage over soil of $\geqslant 50 \mathrm{mg} / \mathrm{kg}$ & 88.2 & 82.5 & 14.0 & 5.3 \\
\hline
\end{tabular}

Data of natural soil and rubber plantation soil in 1982 and the reference system were based on the second soil survey in Hainan (HPSSF, 1993). rubber plantation in Hainan Island.

Rubber tree and litter fresh samples collected were processed timely before nutrients lost (DSCFM, 1993). and dried in a drier with $105^{\circ} \mathrm{C}$ for $20 \mathrm{~min}$. Samples were then taken out and put in a cloth bag to be dried in a drier at $80^{\circ} \mathrm{C}$ for $20 \mathrm{~h}$. The above processed plant samples were then to be grinded in a plant sample grinder and passed with a screen of $2 \mathrm{~mm}$. The samples after screening were finally ready for nutrient analysis. Nitrogen was determined by the semi-micro Kjeldahl method. Phosphorus was determined calorimetrically by the formation of the blue phosphomolybdate complex following reduction with ascorbic acid. Potassium was determined by flame spectrometry(WGH-1A, Huayang Analyse Instruments (HAI) Co. Ltd., Beijing). Total magnesium $\mathrm{Mg}^{2+}$ was analyzed by AAS.

\section{Results}

\subsection{Soil fertility}

With the increase of stand age of rubber plantation, soil fertility decreased all along. From 1954 to 1995, soil organic matter, total $\mathrm{N}$, available $\mathrm{K}$ and available $\mathrm{P}$ decreased $48.2 \%, 54.1 \%, 56.7 \%$ and $64.1 \%$, respectively (Fig.2). Maintaining and improving soil fertility is the key issue for the development of rubber plantation.

The relative declining rates of the main soil nutrients in Hainan rubber plantations are given in Table 1, which are ranked as following: available $\mathrm{K}>$ organic matters $>$ available $\mathrm{P}>$ total $\mathrm{K}$ and available $\mathrm{N}>$ total $\mathrm{N}>$ total
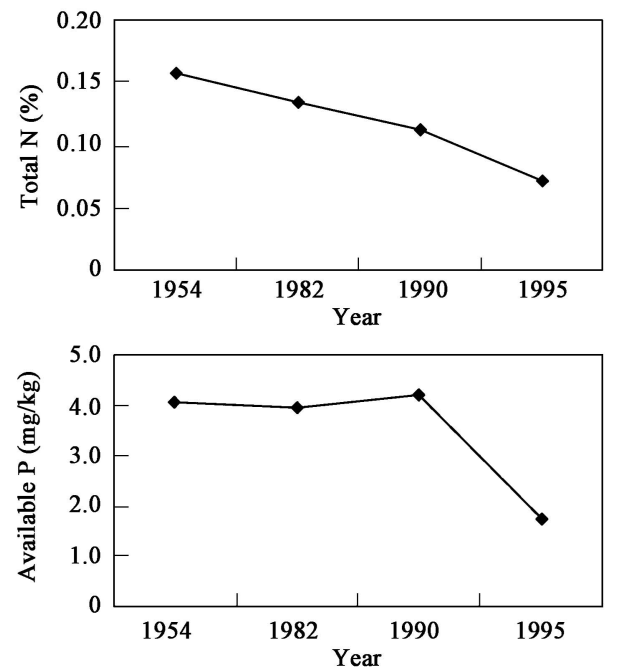
Firstly, dusts attached in the fresh samples were removed 
Table 2 Total amounts of nutrient cycle in rubber plantation of Hainan Island

\begin{tabular}{llll}
\hline Major nutrient elements & $\begin{array}{l}\text { Reserves in rubber plantations } \\
\text { in Hainan }(\mathrm{t})\end{array}$ & $\begin{array}{l}\text { Annual consumption by rubber plantations } \\
\text { in Hainan }(\mathrm{t})\end{array}$ & $\begin{array}{l}\text { Consumption period } \\
(\text { year })\end{array}$ \\
\hline $\mathrm{N}$ & 4363780 & 13229.00 & 329 \\
$\mathrm{P}$ & 671550 & 813.26 & 825 \\
$\mathrm{~K}$ & 535760 & 5698.00 & 94 \\
$\mathrm{Mg}$ & 203870 & 3108.00 & 65 \\
\hline
\end{tabular}

Rubber plantations in Hainan were calculated at $370000 \mathrm{hm}^{2}$, and the soil layer at $40 \mathrm{~cm}$.

P. But they possess similar declining rate ranging from $2.3 \%-5.3 \%$ per year, except for total P.

Table 2 shows that if the complete return of litters was considered without additional fertilizer application to the soil of the rubber plantations, the consumption period for the main nutrient elements of rubber plantations in Hainan was quite different with the order of $\mathrm{P}>\mathrm{N}>\mathrm{K}>\mathrm{Mg}$. The $\mathrm{P}$ consumption period, which could last for 825 years, was the longest and had a great potential. However, Hainan is located in the tropical area and the soil is very clayey and ferrallitic with low $\mathrm{pH}$. The $\mathrm{P}$ is easily absorbed on the surface of oxidants of $\mathrm{F}, \mathrm{Al}, \mathrm{Mg}$ and hydroxides, and becomes a nutrient, which is difficult to be utilized by plants, often causing the shortage of $\mathrm{P}$. The consumption periods of $\mathrm{K}$ and $\mathrm{Mg}$ are only 94 years and 65 years.

\subsection{Carbon sequestration}

The C sequestration of rubber trees is $272.08 \mathrm{t} / \mathrm{hm}^{2}$ within 30-year life period, averaging $9.07 \mathrm{t} / \mathrm{a}$ as indicated in Table 3. It was noticeable that the carbon sequestration of litter played a key role in the carbon fixation of rubber plantation and its proportion accounted for $57.91 \%$ of the total. Not removing the litters for rubber plantation should be treated as an effective measure to improving soil

Table $3 \mathrm{C}$ sequestration of rubber trees within 30-year life period

\begin{tabular}{ll}
\hline Plant components & C sequestration \\
\hline Biomass of rubber tree $\left(\mathrm{t} / \mathrm{hm}^{2}\right)$ & $90.51(33.26 \%)$ \\
$\quad$ Stem + main branch $\left(\mathrm{t} / \mathrm{hm}^{2}\right)$ & 56.25 \\
Secondary and tertiary branches $\left(\mathrm{t} / \mathrm{hm}^{2}\right)$ & 16.13 \\
Roots $\left(\mathrm{t} / \mathrm{hm}^{2}\right)$ & 16.50 \\
Fresh branch $\left(\mathrm{t} / \mathrm{hm}^{2}\right)$ & 10.13 \\
Leaves $\left(\mathrm{t} / \mathrm{hm}^{2}\right)$ & 1.50 \\
Rubber produced $\left(\mathrm{t} / \mathrm{hm}^{2}\right)$ & $24.02(8.83 \%)$ \\
Litters $\left(\mathrm{t} / \mathrm{hm}^{2}\right)$ & $157.56(57.91 \%)$ \\
Total $\left(\mathrm{t} / \mathrm{hm}^{2}\right)$ & $272.08(100.00 \%)$ \\
Mean $\left(\mathrm{t} /\left(\mathrm{hm}^{2} \cdot \mathrm{a}\right)\right)$ & 9.07 \\
\hline
\end{tabular}

fertility.

In comparison with $\mathrm{C}$ sequestration in biomass of rain forest, $234.305 \mathrm{t} / \mathrm{hm}^{2}$ (Li et al., 1998), and C sequestration in biomass of secondary rain forest, $150.203 \mathrm{t} / \mathrm{hm}^{2}(\mathrm{Wu}$ et al., 1998), the rubber forest has more potential on $\mathrm{C}$ sequestration, which is beneficial for reducing global warming effect.

\section{Discussions}

Rubber plantation ecosystem is an important artificial one of Hainan, which constitutes the key pillar industry. All latex products are exported to the mainland. Meanwhile about $1 / 30$ of rubber plantations need to be regenerated each year. $70 \%$ of the wood is also exported to the mainland. The nutrients contained in these products are not involved in the biological cycle and geo-chemical cycle in the Island. This will accelerate the exhaustion of nutrient elements.

The nutrients from annual fertilizer application, litters of the rubber plantations ecosystem and returned from rainfall fail to meet the production and consumption of nutrients, and the nutrients removed from rubber and wood products can not be returned into the system of circulation, resulting in rapid decline in soil fertility in the rubber plantations in Hainan.

With the increase of stand age of rubber plantation, soil fertility decreased all along, including soil organic matter, total $\mathrm{N}$, available $\mathrm{P}$ and available $\mathrm{K}$ (Fig.2). The reason for land degradation under rubber plantation was mainly nutrient imbalance of input and output. Except for P, the outputs of $\mathrm{N}, \mathrm{K}$ and $\mathrm{Mg}$ were more than their input in rubber plantation ecosystem (Table 2). For 30-year rubber plantation the deficits of $\mathrm{N}, \mathrm{K}$ and $\mathrm{Mg}$ per year were 13.07 , 23.41 and $4.07 \mathrm{~kg} / \mathrm{hm}^{2}$, respectively (Table 4).

Each year, thousands of tons of the main nutrient

Table 4 Nutrients cycle of rubber plantation ecosystem in Hainan Island $\left(\mathrm{kg} /\left(\mathrm{hm}^{2} \cdot \mathbf{a}\right)\right)$

\begin{tabular}{|c|c|c|c|c|c|}
\hline \multicolumn{2}{|l|}{ Item } & \multirow{2}{*}{$\begin{array}{l}\mathrm{N} \\
54.09\end{array}$} & \multirow{2}{*}{$\begin{array}{l}\mathrm{P} \\
8.18\end{array}$} & \multirow{2}{*}{$\begin{array}{l}\mathrm{K} \\
37.27\end{array}$} & \multirow{2}{*}{$\begin{array}{l}\mathrm{Mg} \\
12.73\end{array}$} \\
\hline Output & Nutrients fixed by rubber trees & & & & \\
\hline & Nutrients removed by collecting of the seeds & 1.66 & 0.15 & 1.82 & 0.15 \\
\hline & Nutrients removed from the trees by latex tapping & 13.37 & 4.03 & 12.52 & 2.27 \\
\hline & Subtotal & 69.12 & 12.36 & 51.61 & 15.15 \\
\hline \multirow[t]{5}{*}{ Input } & Nutrients returned from litters & 45.00 & 3.00 & 10.00 & 9.00 \\
\hline & Nutrients returned from rainfall & 19.91 & 0.14 & 12.00 & 3.00 \\
\hline & $\mathrm{N}$ fixed biologically & 6.60 & - & - & - \\
\hline & Additional nutrients from fertilizer application & 40.50 & 15.00 & 18.28 & 3.83 \\
\hline & Subtotal & 112.01 & 18.14 & 40.28 & 15.83 \\
\hline \multicolumn{2}{|c|}{ Utilization rate of the returned nutrients $(\%)$} & 50 & 70 & 70 & 70 \\
\hline \multicolumn{2}{|c|}{ Total of possible returned nutrients each year } & 56.05 & 12.70 & 28.20 & 11.08 \\
\hline \multicolumn{2}{|c|}{ Balance of input and output } & -13.07 & 0.34 & -23.41 & -4.07 \\
\hline
\end{tabular}


elements of rubber plantations are consumed for the rubber plantations, and they mainly come from the release of mineral weathering, the rainfall and the return of litters but these sources are limited (Table 2). With the application of various new techniques to rubber production, natural rubber production in Hainan is increasing, leading to more demands for nutrients. Therefore, based on the rational fertilizer application, the complete return of litters to soil should be ensured. Fertilizer application should be made according to the balanced application, the order of nutrient reserves in soil and fertilizer availability. Only in this way can nutrient balance in the system be maintained and sustainable high-yield production of rubber plantation ecosystem can be ensured.

In order to improve soil fertility and achieve sustainable development of the rubber industry, the following measures should be taken: (1) applying fertilizer to maintain the balance of soil nutrients; (2) intercropping leguminous plant to improve soil fertility; (3) reducing the collection of litters; (4) optimizing soil properties to improve element $\mathrm{P}$ availability such as applying $\mathrm{CaCO}_{3}$.

\section{Conclusions}

With the increase of stand age of rubber plantation in Hainan, soil fertility decreased all along. In rubber plantation the balance of input and output on $\mathrm{N}, \mathrm{P}, \mathrm{K}$ and $\mathrm{Mg}$ are $-13.07,0.34,-23.41$, and $-4.07 \mathrm{~kg} /\left(\mathrm{hm}^{2} \cdot \mathrm{a}\right)$ respectively, which show obvious deficits for $\mathrm{N}, \mathrm{K}$, and $\mathrm{Mg}$. If the complete return of litters was considered without additional fertilizer application to the soil of the rubber plantations, the consumption periods for $\mathrm{P}, \mathrm{N}, \mathrm{K}, \mathrm{Mg}$ were only 825 years, 329 years, 94 years and 65 years, respectively. But the $\mathrm{C}$ sequestration of rubber trees accounts for 272.08 $\mathrm{t} / \mathrm{hm}^{2}$ within 30 -year life period and $57.91 \%$ of them were fixed in litters, in comparison with $\mathrm{C}$ sequestration by rain forest $\left(234.305 \mathrm{t} / \mathrm{hm}^{2}\right)$ and by secondary rain forest $\left(150.203 \mathrm{t} / \mathrm{hm}^{2}\right)$, rubber forest has more potentials for $\mathrm{C}$ fixation. The following measures would benefit the maintenance of soil fertility and the development of rubber plantation, including applying fertilizer to maintain the balance of soil nutrients, intercropping leguminous plant to improve soil fertility, reducing the collection of litters, optimizing soil properties to improve element $\mathrm{P}$ availability such as applying $\mathrm{CaCO}_{3}$.

\section{References}

Dale V H, 1997. The relationship between land-use change and climate change[J]. Ecol Appl, 7(3): 753-769.

Dea G B, 1997. Rubber tree Hevea brasiliensis behavior in marginal climatic zones of Cote d' Ivoire: Assessment of ten years observation[C]. Hertfort: Symposium on Agronomy Aspects of the Cultivation of Natural Rubber. IRRDB. 64-67.

DSCFM (Department of Science \& Technology for China Forestry Ministry), 1993. Research methods for forestry ecosystem[M]. Beijing: China Science and Technology Press. 173-176.

Fu B J, Chen L D, Ma K M et al., 2000. The relationships between land use and soil conditions in the hilly area of the loess plateau in northern Shaanxi China[J]. Catena, 39: 69-78.

He K, Huang Z D, 1987. Rubber culture in the north edge of the tropics[M]. Guangzhou: Guangdong Science and Technology Press. 1/2: 170-190.

HPSSF (Hainan Provincial Station for Soil Fertility). 1993. Soil for Hainan Province. Haikou: Hainan Sanhuan Press. 178201.

Jarin G, 1997. Optimum planting density for Hevea production in Thailand[C]. Hertfort: Symposium on Agronomy Aspects of the Cultivation of Natural Rubber, IRRDB. 25-30.

Jiang J S, Wang R S, 2003. Hydrological eco-service of rubber plantations in Hainan Island and its effects on local economic development[J]. J Environ Sci, 15(5): 701-709.

Jiang J S, Wang R S, 2004. Ecology for rubber industry in Hainan[M]. Beijing: China Science and Technology Press. 24-25.

Li Y D, Zeng Q B, Wu Z M et al., 1998. Preliminary study on $\mathrm{C}$ balances in tropical rain forest in Jianfengling region[J]. Acta Ecologica Sinica, 18(4): 371-378.

Liu J G, Linderman M, Ouyang Z Y et al., 2001. Ecological degradation in protected areas: the case of Wolong Nature Reserve for giant pandas[J]. Science, 292: 98-101.

Luo D M, 1986. Intercropping in rubber plantation and soil fertility[J]. Research on Tropical Crops, (3): 11-14.

Sivakumaran S, Kheong Y F, Hasan J et al., 2000. Carbon sequestration in rubber: implications and economic models to fund continued cultivation[C]. Medan: Proceedings for Indonesian Rubber Conference and IRRDB Symposium 2000. 79-102.

Turner M G, 1989. Landscape ecology: the effect of pattern on process[J]. Annual Review of Ecology and Systematics, 20: 171-197.

Wu Z M, Li Y D, Zeng Q B et al., 1998. Study on C pool and effects of cutting in tropical rain forest in Jianfengling[J]. Journal of Applied Ecology, 9(4): 341-344. 